Revista de la red interuniversitaria de estudios sobre las literaturas rioplatenses contemporáneas en Francia

$21 \mid 2020$

Glosolalias transplatinas: fantasmas, utopías y

ficciones lingüísticas

\title{
Xenolinguas, masmédulas y las exofonías del monstruo
}

Xenolangues, masmédulas et les exophonies du monstre

The Xenolanguage, Masmedulas and the Monster Exophony

\section{Pablo Gasparini}

\section{OpenEdition}

\section{Journals}

Electronic version

URL: http://journals.openedition.org/lirico/9633

DOI: $10.4000 /$ lirico.9633

ISSN: 2262-8339

\section{Publisher}

Réseau interuniversitaire d'étude des littératures contemporaines du Río de la Plata

\section{Electronic reference}

Pablo Gasparini, «Xenolinguas, masmédulas y las exofonías del monstruo», Cuadernos LIRICO [En

línea], 21 | 2020, Publicado el 12 julio 2020, consultado el 29 enero 2021. URL: http://

journals.openedition.org/lirico/9633 ; DOI: https://doi.org/10.4000/lirico.9633

This text was automatically generated on 29 January 2021 .

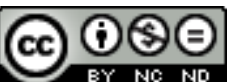

Cuadernos LIRICO está distribuido bajo una Licencia Creative Commons Atribución-NoComercialSinDerivar 4.0 Internacional. 


\title{
Xenolinguas, masmédulas y las exofonías del monstruo
}

\author{
Xenolangues, masmédulas et les exophonies du monstre \\ The Xenolanguage, Masmedulas and the Monster Exophony
}

Pablo Gasparini

1 En 1922, Oliverio Girondo ensaya en Veinte poemas para ser leídos en el tranvía, una escritura poética enunciada por un sujeto en tránsito que registra, de forma fragmentaria e instantánea, diferentes momentos de un viaje predominantemente europeo. En 1925 esta misma visualidad, que Masiello atribuyó al "poder de una Kodak desafiante" (1986: 125), se repite en Calcomanías (1925). Se trata ahora de una serie de estampas de España traídas al discurso por un estricto trabajo de nominación en el que predomina, como lo explica Retamoso (2005), la función designativa del lenguaje. Reducido a un ojo en rápido contrapicado, el poema "Toledo" por ejemplo, recorta, selecciona y describe ángulos urbanos de lejanas reminiscencias pictóricas:

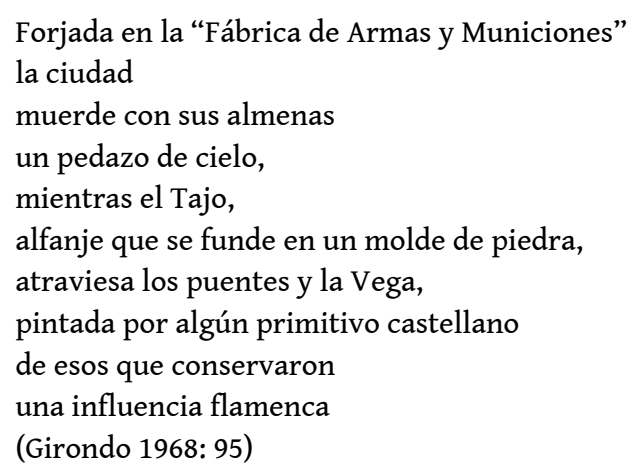

2 Estas instantáneas poéticas de Girondo, estructuradas, al decir de Schwartz, "en torno al tradicional Diario de Viaje" (1996: 217) y que podríamos adscribir a la "poética de la errancia" que Molloy (1984) analiza a partir de Borges y Baudelaire, resultan casi contemporáneas del viaje europeo de otro argentino de vanguardia: Xul Solar.

3 Sabemos que Xul inicia su periplo en Londres en 1912 (ciudad a la que volverá entre 1919 y 1920) y que luego de doce años lo finalizará en París en 1924. Xul recorrerá 
diversas ciudades italianas (Turín, Florencia, Milán, Venecia) y alemanas (Munich, Stuttgart, Berlín), pasando por la capital francesa en diversas oportunidades entre 1913 y 1916. En 1920 expondrá setenta de sus obras en la galería de Arte de Milán y junto a su amigo el pintor argentino Emilio Pettoruti, se contactará con las zonas más consagradas de las artes plásticas vanguardistas. Destacamos la contemporaneidad de los viajes de Girondo y Xul porque es, creemos, la visualidad vanguardista de esta experiencia la que se infundirá en la escritura de San Signos: un registro esotérico de los viajes astrales que el pintor argentino declara haber iniciado en París de la mano del ocultista inglés Aleister Crowley.

4 Por cierto, será al fin de su estadía en Europa que el interés de Xul por las concepciones místicas ya tan presentes en su pintura tendrá un fuerte estímulo a partir de su determinante encuentro con Crowley, uno de los miembros de la Orden de la Golden Dawn, sociedad mágica surgida en Inglaterra en 1888. Traductor de Baudelaire y autor, como sabemos a partir de Toop, de un "Himno a Pan" (2013: 33), Crowley iniciaría a Xul en la experiencia del viaje astral gracias a la técnica de la auto-hipnosis inducida a través de alguno de los trigramas del I Ching o "Libro de las mutaciones".

Patricia Artundo (en Xul Solar 2012: 103-124) ha investigado con su habitual rigor tanto las relaciones entre Xul Solar y Crowley como así también los diarios que el pintor argentino escribió para describir y dejar constancia de sus visiones astrales ${ }^{1}$. Estos registros que le fueran expresamente encomendados por Crowley en 1925 serían organizados por Xul en dos oportunidades (1928-1929 y 1938-1939) en vista de una publicación que no llega a concretar. El libro Los San Signos. Xul Solar y el I Ching (2012) nos permite, gracias al trabajo exegético de la propia Artundo $y$, fundamentalmente, a la labor de establecimiento y traducción de los manuscritos realizados por Daniel Nelson, acceder a este archivo del pintor argentino. De esta escritura esotérica, quisiera destacar inicialmente una enunciación dada al mismo frenesí designativo que encontráramos en Girondo. Como en los dos primeros libros de poesía de este autor, se trata aquí de un despersonalizado "yo" que describe, de forma fragmentaria y portando, al parecer, la misma "Kodak desafiante" (o más bien siendo su propio cuerpo esa Kodak desafiante), los supralunares y coloridos mundos astrales. Al igual que en Girondo, también se apunta detalladamente el momento de la captación de la experiencia. Si en el poema "Toledo" se dejaba constancia del lugar y fecha de su escritura ("Toledo, abril, 1923" (Girondo 1968: 97)) sabemos, por ejemplo, que fue en "noviembre de 1926" que el traveller (o "viajero astral") y su perspectiva habrían ascendido desde un verde plano selvático hasta una altura desde la que irrumpe la visión de una vasta ciudad celestial. Transcribo primero el pasaje en neocriollo, lengua a la que enseguida nos referiremos, y luego la traducción de Daniel Nelson al castellano:

Obsvou por plenselva, verdigal vermifolh', sin ver çeo hasta ke lo cho'veu frenti 'mo mancha prata. Salgou a claro i yi vuel'subu.

Me contravenge una vasta çielciudá de suisantos, fen kestán sólo en fisirela'. El fosair'es un bioenredo de dis vientos c'lores, 'mo cintas disanchas disdensas en pertrafe sobre la noche ras.

Voy observando por una selva plena, con follaje vermiforme de un verde feliz, sin ver el cielo hasta que de repente lo veo en frente de mí como una mancha plateada. Salgo a un claro y allí subo volando.

Me viene en contra una vasta ciudad celestial de santos especiales; parece que sólo están en una relación física. El aire fosforescente es un enredo viviente de vientos de distintos colores, como cintas de distintas anchuras y densidades en circulación continua con la noche en el fondo" (Xul Solar 2012: 60-1)². 

de su asimétrica naturaleza y motivación (uno resultante de un proyecto poético, el otro de una aparente experiencia esotérica) parecen compartir un mismo régimen de visualidad y, de tenerse en cuenta el último libro de Girondo, En la másmedula (1954), una común deriva hacia lenguajes que impugnarán la gramaticalidad y/o legitimidad de las fronteras lingüísticas.

7 En el caso de Xul, desde la propia génesis de los diarios astrales ocurre cierta indiferencia en relación a la normatividad de la lengua a la que se transcribe. En ellos la palabra es, antes que otra cosa, un mero registro de aquello que el viajero astral está vivenciando. La compleja y heterogénea situación enunciativa colabora, además, para esta indiferenciación o indistinción lingüística. Si nos atenemos al dispositivo místico inicial (Xul en trance, Crowley en función de guía-demiurgo y Victor Neuburg -alias Alostrael- en función de transcriptor de las vocalizaciones de Xul), quien verbaliza las imágenes manuscritas por el escriba es menos Xul Solar que su espíritu guiado por el hierofante Crowley. Presuponemos que en este momento la lengua vocalizada sería el inglés, ya que es esa la lengua utilizada por Crowley y Victor Neuburg, quien es el encargado, como ya dijimos, de la transcripción. De esta trama de voces (e idiomas) en la que es difícil establecer con precisión el sujeto de la enunciación, resulta una lengua socavada -aun tratándose del hegemónico inglés- en su gramática, pues ella se encuentra supeditada fundamentalmente, como si se tratase de una telegráfica ekfrasis, a la transmisión de las imágenes astrales. "Grassy plain - gray green - grey in skies Something like Pampas" (Xul Solar 2012: 119) registra Alostrael (Victor Neuburg) a partir de las palabras en inglés del viajero astral Xul en las iniciáticas sesiones en París en mayo de 1924.

8 Como si la masa fónica de la lengua que dice esta experiencia se mostrase predispuesta a conservar la asumida heterogeneidad lingüística y discursiva del dispositivo esotérico que la posibilita, el proceso que la genera irá convocando contribuciones de diversas lenguas. Recordemos que a la sincopada escritura o transcripción de Alostrael le seguirá su ardua reconfiguración por el propio Xul, quien en el primer cuaderno de los San Signos (como llamará a la reunión de estos registros) reescribe: "I saw only a little piece of a Pampa, grey green like mist all around” (2012: 120). Las reescrituras que alientan el al parecer inevitable y reconocido hiato entre imagen mística y palabra del mundo, es decir entre lenguajes o códigos diferentes, no paran allí, ya que a partir de la cuarta visión Xul opta por traducir a un castellano que irá derivando, en un proceso gradual y que sería complejo datar con precisión, a aquello que en 1931 será bautizado por él mismo como neocriollo ${ }^{3}$ o en 1936 como criol, la futur lenguo del Contenente 4 . El criol, surgido entonces a partir de la transposición de la visualidad vanguardista a la lengua, será propuesto por Xul como la lengua de un sujeto continental y se caracterizará por una gramaticalidad escurridiza, altamente inventiva y nunca definitivamente establecida: frente al "Something like Pampas" de Alostrael, una visión de 1926 se referirá a este mismo espacio como "lisa fuspampa, "tla” (2012: 33-1).

9 Si la deriva lingüística de Xul hacia el neocriollo parece hacerse a partir de un arduo proceso de reescritura, la de Girondo obedecería al devenir de su propia poesía. De los iniciales libros de poesía aquí comentados, Girondo pasará por la caligramática experiencia de Espantapájaros (1932), las enfáticas tendencias diegéticas de Interlunio (1937) y la reposición de una poética de corte tradicional en Persuasión de los días (1942) y Campo Nuestro (1946), libro este de marcado sesgo nacionalista. Seguimos en estas 
apreciaciones a Retamoso (2005), quien propone leer, precisamente, la obra poética de Girondo como un devenir que tendrá en En la másmedula (1954) su apogeo o acumulación final, y esto no como resultado de una linealidad sino como el de un "proceso quebrado y de orientaciones múltiples" (140). Este recorrido, que Schwartz (1996) prefiere recortar en períodos diferenciados tal vez para distinguir "la vanguardia cosmopolita de la década del veinte" de "la vanguardia masmedular de los años cincuenta" (219), no omite de todas maneras, en lo que atañe a En la másmedula, un arduo trabajo de reescritura, ya que Girondo republicará el poemario en 1956 y 1966, adicionando nuevos textos y corrigiendo otros.

Un rápido contrapunto entre uno de los poemas masmedulares de Girondo y una de las visiones astrales de Xul podrá hacernos vislumbrar la singularidad y ocasionales afinidades entre ambas experiencias en lo que respecta al trabajo con la lengua. Haremos referencia a un par de ejemplos aquí reunidos por su aparente tema: "Islas sólo de sangre" de Girondo y el fragmento 8 de la Visión 26 de San Signos (su incipit es "Islas van, upa flotan") 5 .

11 De partida, es evidente en el poema de Girondo la desaparición, como lo observa Bonvicino, del orden oracional habitual (1995: 10), lo que acarrea, como veremos, cierto descentramiento del ordenamiento normativo de las categorías gramaticales. Así en el primer verso el sustantivo "videntes" se ve seguido de un sintagma que, al parecer, complementa el adverbio "demasiado" con el pronombre indefinido "nadie" ("Serán videntes demasiado nadie"), posición que desde la normatividad gramatical sólo podría ser completada por un adjetivo. Este tipo de dislocación se repite en otros versos afectando otros órdenes. Por ejemplo, en el tercer verso el sustantivo "gota" condensa el lugar de un genitivo explicativo ("al ritmo gota"), y en el séptimo el pronombre indefinido "algo" se ve seguido por un adjetivo indefinido ("algo mucho"). Se diría que la lengua poética hace rendir aquí el descaso de las categorías y niveles gramaticales para un uso intensivo $y$, como veremos, fundamentalmente rítmico de sus elementos.

12 A la operatoria anterior, que tiene mucho de un "barajar y dar de nuevo" los elementos del lenguaje, se suman ciertos transbordos de una clase gramatical en otra, algo que Bonvicino (1995) prefiere denominar "transferencia funcional" (11) y que Retamoso (2005) analiza en relación al célebre poema "Yolleo", en el que el pronombre sujeto "yo" deviene un verbo ("yollear") o un sustantivo de singulares calificaciones ("el yo mero mínimo"). Este procedimiento que quizás tenga en el poema "El puro no" su máximo rendimiento (con la conversión del negativo "no" en forma verbal -"noan" - y sustantiva -"noes"-), es lateral en el poema que aquí tratamos, aunque vemos la conversión del sustantivo hierba en adjetivo ("herbosos durmientes paralelos"), y el del sustantivo "esqueleto" en verbo ("esqueleteando el aire"). Estos descentramientos y traslados dispersivos de los órdenes gramaticales se dan además en una sintaxis en que la ausencia de toda puntuación libera sus elementos de las sujeciones jerárquicas usuales permitiendo, especialmente en "Islas sólo de sangre", el "entrometimiento" de verbos en primera persona en estructuras regidas por un orden en todo caso apositivo ("Son borra viva cato descompases tirito de la sangre", "laxas fibras orates en desparpada fiebre musito por mi doble").

13 Esta conversión de la lengua legítima (en el sentido de Bourdieu 2001: 67-98) en un estallido en el que, en todo caso, podemos detectar la regularidad de ciertos procedimientos, difiere en buena medida de la propuesta de lengua de Xul Solar. Aunque en una primera lectura el trabajo de Xul con el léxico afecte su inmediata 
legibilidad, la organización de los elementos responde a una lógica gramatical reconocible. En la primera frase del fragmento escogido ("Islas van, upa flotan con mui boskes i pópulo, con marañas de xus rufas raizes, colgin long, sierpi") no hay mayores inconvenientes en identificar el sujeto de los verbos "van" y "flotan" e incluso desde la perspectiva del análisis estructural más tradicional podemos notar un par de complementos circunstanciales ("con mui boskes i pópulo", "con marañas de xus rufas raizes") cuya recurrencia no afecta la sintaxis estándar de cualquier lengua latina. Se trata de una diferencia importante respecto a la masmedular lengua de Girondo, pues si quisiéramos acercar un argumento que fortaleciera cierta filiación de la poética de En la masmédula a la tradición neobarroca, tal como lo ha apuntado en 1986 Aldo Pellegrini (en relación, en verdad, a lo barroco) y desarrollado Schwartz (1996), sin dudas podríamos observar, siempre a partir del poema que hemos seleccionado, como la proliferación de predicaciones a partir de un sujeto aparente ("Serán videntes (...)", "Son borra viva (...)", "son estertores malacordes (...)", "son pedales sin olas (...)") parece menos caracterizar ese sujeto que disolverlo a partir del distanciamiento de toda expectativa de una predicación objetiva.

Debemos recordar en este momento que la lengua de Xul se pretende registro fiel de sus visiones, una mimesis de sus viajes astrales, tal como dirá de sus propias pinturas, a las que pensaba como realistas por plasmar la realidad supralunar. En la masmédula, como se ha señalado en diversas ocasiones, se libera de toda referencialidad o, en todo caso, la forma en que alude a su propio mundo se da, para decirlo con Meschonnic, a partir del ritmo como "organização subjetiva do discurso" (2006: 17). Queremos decir con esto que aspectos rítmicos en su acepción más tradicional (los heptasílabos y alejandrinos que, según Schwartz (1996) se ocultan en esta escritura) ${ }^{6}$, la utilización de la espacialidad y del blanco de la página, la alternancia de términos y a veces de morfemas al interior del verso, están dados al servicio de la inscripción de un sujeto que se dice en la imprevisibilidad de los movimientos de su oralidad, aquella que el proprio Girondo se encargó de grabar en la versión discográfica de 1962 de este libro. Frente a esta singularidad rítmica que permite percibir el movimiento de una voz en la escritura, la experiencia de Xul parece plasmar un sujeto que, aun en las diferentes modalidades de su viaje astral ${ }^{7}$, se organiza discursivamente en razón de la experiencia de su viaje y no de la particular escansión de su voz contenida, de forma predominante, en los moldes o skhema rítmico de un prosaísmo convencional. Sin entrar en la polémica abierta por Daniel Nelson (en Xul Solar 2012:47) acerca del carácter poético de los San Signos, pues para ello debería ofrecerse antes algún concepto a priori de lo que se entiende por poesía, algo que no es el objeto de este trabajo, sobran elementos para apuntar que mientras que la lengua de En la masmédula puede entenderse como una lengua poética, el neocriollo surgido de la reescritura de los diarios astrales es una lengua con la que puede traducirse y aun escribirse poesía (como cuando Xul traduce los aforismos de Mongestern), pero que no implica por sí misma esa condición ${ }^{8}$.

Todas estas consideraciones quizás sean relevantes para entender el aspecto que más aproxima a Girondo y Xul, la utilización común del tan vanguardista recurso neológico. En el octavo fragmento de la visión 26, nos encontramos con muchos de ellos, entre otros con "mantestas" (cabezas humanas), "biolagos" (lagos vivientes), "man'fauna" (fauna humana), "mampexes" (peces humanos), "luzpuntos" (puntos de luz), y aun con el neologismo verbal "se diamezclan" (se cruzan y se mezclan). En el poema de Girondo, aun sin hacer de este recurso un elemento principal como ocurre por ejemplo en "Mi Lumia" (con los célebres "lubidulia", "golocidalove", "enlucielabisma" y 
"descentratelura", entre otros), podemos encontrar "nubecosa", "malacordes y "grifosones". De partida vemos en los neologismos de Xul un aspecto multilingüe ("man" más alguna palabra del español -fauna-, del español o italiano -testa- o del portugués -pexes por, quizás, peixes-), mientras que en Girondo los neologismos se construyen casi exclusivamente con palabras del propio castellano (grifo-sones), y aun con insinuaciones o alusiones que para reverberar algún sentido deben proyectarse sobre esa lengua (enlucielabisma: algo que, tal vez, se abisme y se encienda en luz). Lo sorprendente es que si los neologismos de Xul logran decodificarse es, en parte, gracias al multilingüismo de sus vocablos que apuntan, por lo común, a su sentido lexicográfico fuerte, mientras que los neologismos de Girondo se abisman (para rescatar el verbo) en un carácter plenamente connotativo.

16 La apertura del neocriollo a diversas lenguas no sólo puede ser pensada, como lo sosteníamos más arriba, a partir del dispositivo esotérico que sirvió de base escritural a sus primeros ejercicios, sino también, y quizás fundamentalmente, a su escucha de la Babel porteña de los años 20. Quizás por asentarse, como afirma Rodeiro (2008: 217) sobre el lenguaje hablado (gran parte de su grafía procura remedar lo oral), el neocriollo no ofrece reparo a los aportes inmigratorios. Escuchamos en él, por ejemplo, el italianado vocablo facha-que más adelante utilizaría Virgilio Piñera como posibilidad para el polaco geba durante la antológica traducción de Ferdydurke de Gombrowicz- o expresiones populares del tipo "me debilu i fiacu" por "me debilito y me da fiaca", entre otros elementos que hemos analizado en un trabajo anterior (Gasparini 2019). Más bien tendiendo hacia el créole (en su sentido caribeño), el criol o neocriollo supone la emergencia de todo aquello que la predisposición "acriollante", atenida siempre a la construcción de lo nacional a partir de lo estrictamente rural, había evitado.

Recordemos, para ilustrar la reticencia criollista a la heterofonía inmigratoria, el prefacio original de Fervor de Buenos Aires (1923) en el que Borges se declara refractario a "la vocinglera energía de algunas calles centrales y la universal chusma dolorosa que hay en los puertos" (Borges 1923: sp). Se trata de un preferir no oír que Sarlo ligará a cierta resistencia ideológica de la vanguardia criollista (1995: 42) ${ }^{9}$. Como lo expone el “Suplemento explicativo de nuestro 'Manifiesto", texto publicado en el número 8-9 de la revista Martín Fierro (1924), esta reticencia se da en un debate mayor, el del rechazo a las concepciones literarias que la revista atribuye a los autores de "pronunzia exótica", un acento del que el grupo martinfierrista (autodesignándose como "argentinos sin esfuerzo") busca apartarse ${ }^{10}$. La lengua creada (e incesantemente recreada) por Xul, nada tiene de aquella "disciplina abstracta de la imaginación racional" que Sarlo (1995: 161) encuentra en la fascinación de Borges por las lenguas abstractas y que entiende como aséptico refugio frente al altisonante y confuso aluvión inmigratorio. En los materiales que el criol convoca, tampoco encontramos una mirada nostálgica e idiosincrática hacia el extinto gaucho, convertido en fundamento patrio desde El payador de Lugones (1916). La única alusión que se esboza sobre esta figura atávica es la de un gaucho desterritorializado (Xul Solar 2012: 58-1), entrevisto a partir de una concepción esotérica de su indumentaria que anticipa el poncho místico con el que el brasileño Arthur Bispo do Rosario se presentaría ante la divinidad (ver Aguilar 2000). Se trata de indicios importantes de la no sujeción del criol a lo criollista, que pasa fundamentalmente, sin embargo, menos por la constitución en sí de la lengua o por los materiales movilizados, que por una disposición a la escucha de aquello que en la 
década del cuarenta (como enseguida veremos) será simbolizado, con evidente intencionalidad política, como la lengua del monstruo.

En Los muertos indóciles, Rivera Garza (2013) rescata el concepto de exofonía de Marjorie Perloff para referirse a toda escritura que abrace "la condición migrante de la lengua" (133). Es esta condición la que Xul parece no sólo plasmar en la forma del neocriollo, sino también representarse reiteradamente en la experiencia que le habría dado, como vimos, su impulso inicial. Frente a la no escucha criollista de la "vocinglera energía" o al directo rechazo de la "pronunzia exótica", son incesantes en los San Signos las escenas en que el espíritu de Xul se muestra como un espíritu no sólo dado a la visión, sino también "a la escucha" y aun a la escucha de lo que por el momento le resulta extranjero e ininteligible. En la visión 24 (fragmento 7), por ejemplo, se registra que "aparezel ángel, chico, mo entre nubes, i le pidu mesplike, me conteste con dos vozes en lingua ke no calu" ("aparece el ángel, pequeño, como entre nubes, y le pido que me explique. Me contesta con dos voces en una lengua que no entiendo"), y en la visión 28 (fragmento 3) se depara, ornado de un pentagrama, con un dios cuya lengua tampoco logra comprender: "i entón el divo en longa perora en lingua ke no calu pracante su plurtoile kes 'truye, qypne, doke, per." ("y entonces el dios en una peroración larga en una lengua que no entiendo canta a su lado su múltiple trabajo, que es construir, hipnotizar, enseñar constantemente").

El no encuadramiento -para hablar con Nancy- de estas vocinglerías astrales a un "sistema de reenvíos significantes" (2014: 63) no amedrenta a este sujeto o alma que se quiere decididamente oyente. Antes bien, los "vozeríos de toas las linguas" (Xul Solar 2012: 36-12) con los que se depara en sus flaneos espirituales supone una proteica disparidad sonora dada a la multiplicación y posibilidad de incesantes sentidos (el "sensi y rgu'per neo", (36-12)) cuya significación o reenvío significante se suele posponer, confiada y despreocupadamente, para un futuro de, quizás, mayor apertura clarividente. Deparado en la visión 57 (fragmento 3) con unas prístinas islas de las que caen cataratas de una crema espesa que no parece ser otra cosa que "vieqas lembras i empirias condensias" ("viejas memorias y experiencias condensadas") -todo un reverso de lo que en el mundo sería "libría de mui libros mo léxicos en xenolingua" ("una biblioteca de muchos libros que son como léxicos en una lengua extranjera")- el viajero astral admite sus limitaciones y se esperanza con entender esa xenolingua en otro momento ("en xenolingua ke no sabu i dequ pa otra vez"). No hay así en Xul recelo o suspicacia ante la pura materialidad de una lengua que no se comprende, sino más bien predisposición y esperanza de futura comprensión.

En carta a Córdoba Iturburu, Oliverio Girondo confiesa, quizás por primera vez, la sorpresa que le causa la presunta ilegibilidad de En la masmédula: "En cuanto a lo que me dices sobre los poemas no puedo ocultarte que me sorprende que los encuentres ininteligibles" (Schwartz 2007: 375). Se trata de una no escucha crítica que, como podemos constatarlo en carta a Ricardo Paseyro, lo aflige especialmente por lo que significa de escasa y pobre recepción ("Las tres notas bibliográficas sobre él aparecidas hasta ahora son de una chatura inigualable" (379)). Como lo sintetiza Enrique Molina en el estudio que serviría de prólogo a la edición de En la masmédula por editorial Losada, el último libro de Girondo fue recibido con silencio e incomprensión: "Su aparición fue recibida con el silencio reticente de la estulticia, cuando no con los balbuceos desorientados de quienes imaginan reducir la envergadura de una obra excepcional a su propia incapacidad de acceder a la poesía" (Girondo 1968: 40). Según Gonzalo Aguilar 
esta sordera crítica obedecería a la opción de Girondo por "la experimentación vanguardista en un marco cultural que no favorecía este tipo de práctica" (2003: 184), y podría explicarse en razón de la propia poética de En la masmédula que ofrece, disonantemente, en un momento de regreso al "mundo armónico y humano, de lirismo pleno"(183), una poética de la pura materialidad y sonoridad, o como prefiere describir Sebastián Bianchi en una reseña de nuestros días, una poética "destinada a las orejas" donde lo sonoro "golpea el abecedario agrupando consonantes con vocales que se comportan como verdaderas campanas o cencerros, grillos que mediante el hueco de su lira van multiplicando la onda acústica mientras las letras se friccionan" (2019 Web). Para poder escuchar esta poética en la que "la denotación, se ha trocado en un puro juego de alusiones y desplazamientos semánticos producto de una fonética inventada" (2019 Web) se precisa cierta despreocupación ante la ansiedad por el sentido y cierto goce ante la irrupción de la novedad sonora y prosódica: exactamente aquellas capacidades que ostenta el espíritu astral de Xul frente a la resonante materialidad de las xenolinguas. Las enseñanzas que Xul recibe de un alto ser astral para potenciar su clarividencia podrían ser así una sintética muestra de la crítica de la que Girondo careció. La visión 21 (fragmento 5) reza precisamente toda una propedéutica de la inestabilidad lingüística: "Símbolos valgan si xe magiusan. No son lingua estable" ("Los símbolos valen si se usan mágicamente. No son una lengua estable").

Podríamos esbozar a partir de aquí una tesis glotopolítica. La vocinglería de la "chusma" portuaria, o sea las sonoridades de la inmigración, sería rechazada por el criollismo aunque contrabandeada por el heterodoxo Xul en el interior mismo de la revista Martín Fierro bajo la forma de una lengua, el criol, plasmada inicialmente para decir una experiencia astral. Se trata de una irrupción significativa, porque no sólo contrabandea, hace escuchar, los sonidos y palabras silenciados, sino que los inscribe en escenas pedagógicas de amplitud del campo auditivo, una reorientación de la escucha no a lo directamente denotativo sino a la materialidad y a su promesa de sentido. Si insistiéramos en esta lectura glotopolítica y rescatáramos otros momentos de este ostracismo de lo exofónico al margen o a lo degradado, la operatoria de Xul podría ser leída con repercusiones aún más amplias. Por ejemplo la utilización del lunfardo y de la dinámica del cocoliche para la construcción de la voz de un nuevo subalterno ya no rural sino suburbano en "La fiesta del monstruo" de Bustos Domecq $(1947)^{11}$, nos permitiría leer el contrabando de Xul como una anticipada desconstrucción de aquello que Masiello, apoyada en la brillante lectura de Piglia (2005) sobre el juego de voces en "Los crímenes de la calle Morgue", llamaría "la fantasía del monstruo" (Masiello 2013: 217). Así si Piglia destaca que este relato de Poe se construye en la tensión entre "El monstruo: el que viene de afuera, del otro lado de la frontera y cuya voz es extranjera; el otro puro" y "El enigma: lo que no se comprende, lo que está encerrado; el adentro puro" (2005: 85), podríamos concluir que Xul transforma la extranjera vocinglería del monstruo en enigma, convocando así ya no el temor capaz de hacer del otro un animal, sino la esperanza de revelación que guarda en potencia lo que aún no se comprende.

Superadas las tensiones en relación a la lengua nacional, y aun en la inminencia de un momento político que se querrá neutralizador de la subalternidad sublevada, el antiguo martinfierrista Girondo, ya a mediados de la década de 50, hará de la propia poesía el espacio exofónico antes reservado a la vocinglería inmigrante. No se trata aquí, como en Xul, de rescatar la proteica variedad multilingüe, sino de que la propia lengua, el castellano, devenga, extrañándose y desmenuzándose sobre sí mismo, sonora alteridad; 
una xenolingua (podríamos decir, de tomar el término neocriollo del Xul) que convoca, para poder ser inteligible, la predisposición a la escucha de una prosodia otra, precisamente aquella predisposición de la que se enorgullecían de prescindir los "argentinos sin esfuerzo" de Martín Fierro. Girondo, como lo registra su propia elocución en la grabación discográfica, nos habla como si fuese, de hecho, aquel "divo en longa perora" con la que se topa, entre otros, el traveller Xul. Su voz está hecha de la gravedad y ampulosidad de quien, sabiéndose enigmático, aguarda la escucha de quien sea digno de escucharlo. Si, como lo leyó Viñas, habitaba en su previo transtelurismo un gesto aristocrático (2005: 57), aquí se trata de la aristocracia de quien, como lo constata reiteradamente el espíritu de Xul, aguarda la elevación como condición de su audiencia. El hecho de que lo que se ofrezca a la escucha sea menos la consolidación de un lenguaje que su, como vimos, metódica trituración, nos habla de un viaje entrópico, a uno de esos mundos que, como abundan en los San Signos, están hechos menos de estabilidades que de las múltiples posibilidades del caos. Ya sea por cansancio "de tanta tanta estanca remetáfora de la náusea" o de las "ideítas reputitas y de las ideonas reputonas" (Girondo 1968: 460), Girondo hace estallar, cual derridiano Dios en Babel ${ }^{12}$, la pretensión de cualquier pertenencia (castellana, criollista, etc.) en la lengua. Sobre las esquirlas de ese estallido hay sólo un ritmo, el de su Voz.

Girondo y Xul no comparten así tan sólo una misma visualidad, aquella incansable Kodak vanguardista de la que nos habla Masiello, sino que también su dispar producción se da en el contexto sonoro de las lenguas de viaje y aun de los sonidos de aquellos otros que han tomado, que han perturbado, los sonidos usuales de la casa. Para decirlo sin mayores metaforizaciones, no es forzado leer ambos artistas en relación a la alteridad lingüística argentina. Sobre ese abigarrado y polifónico campo, Xul, un espíritu entre otros, construye (por condensación de muchas) una lengua; Girondo, por el contrario, la desmigaja. Ambos, de más está decirlo, trabajan con la lengua plásticamente, la perciben, a la manera de Artaud, bajo su aspecto "físico y afectivo" (1999: 140). Que Xul haya montado y prefigurado la recepción auditiva del Girondo masmedular nos habla, por último, de su esperanzosa y expansiva permeabilidad frente a la retumbante y centrípeta fuga girondina hacia el silencio final.

\section{BIBLIOGRAPHY}

AA.VV., "Suplemento explicativo de nuestro Manifiesto. A propósito de ciertas críticas", Martín Fierro $\mathrm{N}^{\circ} 8$ y 9, segunda época, año 1, agosto-septiembre 1924, Buenos Aires, p. 56.

Aguilar, Gonzalo. Poesía concreta brasileña: las vanguardias en la encrucijada modernista, Rosario, Beatriz Viterbo Editora, 2003.

Aguilar, Nelson (ed.), “Arthur Bispo do Rosario”, Mostra do redescobrimento. Imagens do inconsciente, Fundação Bienal de São Paulo, São Paulo, 2000, p. 204-245.

Artaud, Antonin, “Cartas sobre a linguagem”, O teatro e seu duplo, São Paulo, Martins Fontes, 1999. Traducción de Teixeira Coelho, revisada por Monica Stahel. 
Bianchi, Sebastián, “Afonía clásica”, Bazar Americano º 73, año XI, septiembre-octubre 2019, Web. Consultado el 15 de noviembre de 2019.

Bonvicino, Régis, “Antes que se dilate a pupila do zero”, Oliverio Girondo, A Pupila do Zero En la Masmédula, São Paulo, Iluminuras, 1995, p. 9-218. Traducción, selección y estudio preliminar a cargo de Régis Bonvicino.

Borges, Jorge Luis, “A quien leyere”, Fervor de Buenos Aires, Buenos Aires, Imprenta Serantes, 1923. Bourdieu, Pierre, Langage et pouvoir symbolique, Paris, Fayard, 2001.

Derrida, Jacques, Torres de Babel, Belo Horizonte, Editora UFMG, 2006. Traducción de Junia Barreto.

Gasparini, Pablo, "Del babelismo como espacio: Xul en criol", Bergero-Mandolessi (ed.), Sujetos, territorios e identidades en tránsito, Stanford, Stanford University, 2019, p. 124-139.

---, "De la inmunda media lengua como lalengua (sobre voz, lengua y comunidad en 'La fiesta del monstruo' de Bustos Domecq)", Olmos-Palmero Gonzalez (ed.), Textualiddes transamericanas e trasatlânticas, Rio de Janeiro, Abralic, 2018, p. 89-98.

Girondo, Oliverio, Obras Completas. Buenos Aires, Losada, 1968.

Masiello, Francine, El cuerpo de la voz, Rosario, Beatriz Viterbo Editora, 2013.

---, Lenguaje e ideología. Las escuelas argentinas de vanguardia, Buenos Aires, Hachette, 1986.

Meschonnic, Henri, Linguagem, ritmo e vida, Belo Horizonte, FALE/UFMG, 2006. Traducción de Cristiano Florentino, revisada por Sonia Queiroz.

Molloy, Silvia, "Flaneries textuales: Borges, Benjamin y Baudelaire”, Lía Schwartz Lerner e Isaías Lerner (compiladores), Homenaje a Ana María Berrenechea, Madrid, Castalia, 1984.

Nancy, Jean-Luc, À escuta, Belo Horizonte, Edições Chão da Terra, 2014. Traducción de Fernanda Bernardo.

Pellegrini, Aldo, “La poesía de Girondo”, Oliverio Girondo, Aldo Pellegrini (ed.) Buenos Aires/ Barcelona, Argonauta, 1986.

Piglia, Ricardo, El último lector, Buenos Aires, Anagrama, 2005.

Retamoso, Roberto, Oliverio Girondo: el devenir de su poesía, Rosario, UNR, 2005.

Rivera Garza, Cristina, Los muertos indóciles. Necroescrituras y desapropiación. México, Tusquets, 2013.

Rodeiro, Matías, “Xul. Más allá del idioma (de los argentinos)”, González, Horacio (ed.), Beligerancia de los idiomas. Un siglo y médio de discusión sobre la lengua latino-americana, Buenos Aires, Colihue Universidad, 2008, p. 185-252.

Sarlo, Beatriz, Borges, un escritor en las orillas, Buenos Aires, Ariel, 1995.

Schwartz, Jorge, "La trayectoria masmedular de Oliverio Girondo", Cuadernos Hispanoamericanos N553-554, julio-agosto1996, p. 217-230. , Oliverio: nuevo homenaje a Girondo, Rosario, Beatriz Viterbo Editora, 2007. , "Sílabas as Estrelas componham: Xul Solar e o neocriollo", Fervor das vanguardas. Arte e Literatura na América Latina, São Paulo, Companhia das Letras, 2013, p. 148-177. Schwartz Lerner Lía y Lerner Isaías (ed.), Homenaje a Ana María Barrenechea, Madrid, Castalia, 1984. 
Toop, David, Resonancia siniestra. El oyente como medium, Buenos Aires, Caja Negra, 2013.

Traducción de Valeria Meiller.

Viñas, David, Literatura argentina y política.1 De los jacobinos porteños a la bohemia anarquista, Buenos Aires, Santiago Arcos Editor, 2005.

Xul Solar, Entrevistas, artículos y textos inéditos, Patricia Artundo (ed.), Buenos Aires, Corregidor, 2005.

Xul Solar (et al.), Los San Signos: Xul Solar y el I Ching, Buenos Aires, Fundación Eduardo F. Constantini-Fundación Pan Klub, 2012.

\section{APPENDIXES}

Islas sólo de sangre

Serán videntes demasiado nadie

colindantes opacos

orígenes del tedio al ritmo gota

topes digo que ingieren el desgano con distinta apetencia

Son borra viva cato descompases tirito de la sangre

Un poco nube cosa entre sienes de ensayo

y algo mucho por cierto indiscernible esqueleteando el aire

dados ay derrumbe hacia el final desvío de ya herbosos durmientes paralelos

son estertores malacordes óleos espejismos terrenos

milagro intuyo vermes

casi llanto que rema

de la sangre

Sus remordidas grietas

laxas fibras orates en desparpadas fiebre musito por mi doble

son pedales sin olas

huecos intransitivos entre burbujas madres

grifosones infiero aunque me duela

islas sólo de sangre

(Girondo 1968: 409)

Islas van, upa flotan con mui boskes i pópulo, con marañas de xus rufas raizes, colgin long, sierpi. Lagos van, floxos flotan, enundan lu ke tocan, son entre agua i nube, plic'lór sedi. Su fauna es 'man'gente mimeti péxoide, con 'mantestas. Creu kestos biolagos llevan su 'man'fauna do ésta kiere, envés kest'autonade, i los mampexes ke diferan da mayoría d'rivan dootri. Los lagos ke flótros do no congenian se apartan pa no choke, i los ke sí, se diamezclan, 'mo tudo akí, hasta el agua i el fuego, i estofa con noia. El firmamento es difusa luz rósea i oro, mo fueivía láctea. ji vae mi çieláñora, tal ke me almu más, ke logo estou en otro surmundo blis: cuasi mar de cucuios, con gran fos parches, róseos i arrebol. Es difícil ir por este aire tan denso, iden más de luzpuntos. (Xul Solar 2012: 26-8) 


\section{NOTES}

1. Artundo. "Primera historia de un Diario Mágico" en Xul Solar 2012, pp. 103-124.

2. La paginación de esta obra abarca sólo los textos críticos, por lo cual indicaremos los textos específicos de Xul Solar con los números de la visión y del fragmento correspondiente. Las traducciones del texto original de Xul son todas de Daniel Nelson.

3. Me refiero a "Apuntes de neocriollo", que aparece por primera vez en Azul. Revista de Ciencias y Letras (Xul Solar 2005: 164)

4. En "Visión sobre el trilíneo" (1936) publicado en Destiempo (Xul Solar 2005: 168). Sobre la génesis y formación del neocriollo, ver Schwartz (2013).

5. En nuestro Anexo transcribimos ambos textos.

6. "La fuerza del clásico alejandrino (representado por uno de sus hemistiquios heptasilábicos), escondido en la percepción visual de la página, se revela con intensidad en la cadencia rítmica de la oralización y en la inevitable escansión silábica del verso" (Schwartz 1996: 228). En el poema aquí trabajado, podemos escuchar el heptasílabo en los versos segundo, noveno, undécimo, duodécimo, decimocuarto, decimosexto, y en el decimonoveno, "islas sólo de sangre," que da nombre al poema. También lo podemos encontrar "escondido" al final del décimo verso ("espejismos terrenos") y, si se quiere, podemos leer el largo decimoquinto verso como una combinación de tres heptasílabos (el verso se compone, por cierto, de tres núcleos prosódicos y semánticos: "laxas fibras orates", "en desparpada fiebre", "musito por mi doble"). El alejandrino, compuesto de dos heptasílabos con cesura, lo encontramos en el sexto y decimoséptimo verso. $\mathrm{Y}$ aún, si queremos, podemos encontrar endecasílabos en el primer y tercer verso.

7. Artundo nos recuerda que en estos diarios astrales se distinguen tres tipos de intensidad, la "Simple Spirit Visión", la "Travelling in the Spirit Visión" y finalmente la "Rising in the Planes", en la que además de percibir la imágenes como volúmenes, el traveller podría interactuar con los mundos visitados (en Xul Solar 2012: 74).

8. Sobre la traducción al neocriollo de Cristian Morgenstern, ver "Algunos piensos cortos de Cristian Morgenstern", publicado en Martín Fierro, 1927 (Xul Solar 2005: 113-116). Sobre la condición poética del neocriollo consideramos que, a pesar que aquí resistimos una lectura en ese sentido, un elemento para el debate lo constituye el hecho de que Xul llame "Poema" a una de sus visiones publicadas en la revista Imán, 1933 (en Xul Solar 2006: 161).

9. "Los debates acerca de la legitimación cultural atraviesan las revistas literarias de los años veinte: los 'criollos viejos' que hegemonizan Martín Fierro y Proa no están dispuestos a admitir fácilmente que una lengua para la literatura pueda ser producida también por escritores cuyos padres no habían nacido en Argentina, cuyo acento era barrial, marginal, e incorporaba marcas de origen inmigratorio" (Sarlo 1995: 42).

10. “Todos somos argentinos sin esfuerzo, porque no tenemos que disimular ninguna 'pronunzia' exótica...” en Martín Fierro, segunda época, año 1, n. 8-9, agosto-septiembre 1924.

11. Trabajo centralmente esta cuestión en Gasparini (2018)

12. Nos referimos a la lectura que Derrida (2006) formula sobre el mito de Babel.

\section{ABSTRACTS}

The article compares the linguistic experiments of Xul Solar in San Signos (2012) and Oliverio Girondo in En la masmédula (1954). Both writings are analyzed based on the modernist context 
and its conflicts with the Argentine immigration process. This perspective reveals affinities (the visuality of the common experience of the travel) and asymmetries, especially those related to listening to the alterity sound or exophony (Rivera Garza 2013). The article proposes to understand the acoustic predisposition of Xul Solar as the ideal critical framework for the reception of the poetics of En la masmédula.

El artículo compara las experimentaciones lingüísticas de Xul Solar en San Signos (2012) y de Oliverio Girondo en En la masmédula (1954). Ambas escrituras son analizadas a partir del contexto vanguardista y de los conflictos de este con el proceso inmigratorio argentino. Esta perspectiva revela afinidades (la visualidad de la común experiencia del viaje) y asimetrías, especialmente las referidas a la escucha de la alteridad sonora o exofonía (Rivera Garza 2013). El artículo propone entender la predisposicion acústica de Xul Solar como el marco crítico ideal para la recepción de la poética de En la masmédula.

L'article compare les expériences linguistiques de Xul Solar dans son San Signos (2012) et d'Oliverio Girondo dans En la masmédula (1954). Ces écritures sont analysées en fonction de leur contexte avant-gardiste et de leurs conflits avec le processus d'immigration argentin. Cette perspective révèle des affinités (la visualité de l'expérience commune du voyage) et des asymétries, en particulier celles liées à l'écoute de l'altérité sonore ou de l'exophonie (Rivera Garza 2013). L'article propose de comprendre la prédisposition acoustique de Xul Solar en tant que cadre critique idéal pour la réception de la poétique de En la masmédula.

\title{
INDEX
}

Palabras claves: neocriollo, criol, vanguardia, inmigración, glotopolítica

Mots-clés: neocriollo, criol, avant-garde, immigration, glottopolitique

Keywords: neocriollo, criol, Xul Solar, modernism, immigration, glotopolitics

\author{
AUTHOR \\ PABLO GASPARINI \\ Universidade de São Paulo (USP) \\ pablogasparini@usp.br
}

